

\title{
The Impact of Public infrastructure on the Productivity of the Chilean Economy
}

\author{
J.M. Albala-Bertrand and E.C. Mamatzakis
}

February 2001

\begin{abstract}
The aim of the present study is to assess the effect of public infrastructures on the cost structure of the Chilean economy, and thereby on productivity, differentiating between two key sequential periods. A derived aim is to establish to what extent infrastructure and non-infrastructure capitals are related. Our conclusions appear to indicate that infrastructure capital reduces the production cost of the economy, thereby increasing productivity, only in the second period. In turn, noninfrastructure capital appears to be mostly unrelated to infrastructure capital in the first period, but to be clearly complementary in the second period. In addition, infrastructure capital and labour appear to be substitutive in the first period, but mostly unrelated in the second period. Complementarity, neutrality and substitution can to a large extent be explained by the dramatic differences in the institutional structures between these two periods.
\end{abstract}

Key Words: Infrastructure, Chilean Institutional Change, Translog Cost Function

JEL Classification: H54, O4, C3

Address: Dr J.M. Albala-Bertrand., Department of Economics, Queen Mary, University of London, Mile End Road, London E1 4NS, Email: J.M.AlbalaBertrand@qmw.ac.uk; Tel:020 7882 5094, Fax: 0208983 3580; Dr E. Mamatzakis, City University Business School, Frobisher Crescent, Barbican Centre, London EC2Y 8HB, Tel: 0207477 0133/8885, E-mail: E.Mamatzakis@city.ac.uk 


\section{Introduction}

The aim of the present study is to assess the effect of public infrastructures on the cost structure of the Chilean economy and thereby on productivity. A derived aim is to establish to what extent and how infrastructure and non-infrastructure capitals are related.

Chile endured significant policy swings over our sample, 1960-98, period. The Chilean economy switched from a mixed economy with predominant direct state participation (1960-1970) to one with a negligible direct state contribution (1984-1998). It passed through ideological bouts of strong nationalisation and regulation in the 1970-73 period and a strong privatisation and purist economic neo-liberalism in the 1974-1983 period (Parkin, 1983). The1960-1973 period is normally associated with a regime of import substitution in which the state represented the leading development drive, i.e. a structuralist-developmentalist type of regime (Meller, 1990; Ffrench-Davis, 1973). In turn, the 1974-1998 period represents a neo-liberal, export-orientated, regime with only a very secondary economic role for the state, i.e. a "Washington Consensus" type of regime (Albala-Bertrand, 1999, Taylor, 1993). The latter normally perceives the public sector as both negatively interfering with the "free market" and imposing "crowding out" on private investment to the detriment of the economy (Bosworth et al, 1994; Wisecarver, 1992).

The latter change imposed onto Chilean economy and society was much more than one of "policy regime". It constituted a dramatic change on the institutional structure over which the economy and its dynamics had operated until then. There was a wholesale domestic deregulation, external liberalisation and general privatisation of the economy. In this 
scheme of things, the public sector was relegated to a purely subsidiary role in both production and resource allocation. The private sector, in turn, was elevated to the status of main economic initiator, which responded to the allocation and signalling mechanism of a supposedly unshackled market (Velazco, 1994; Bothworth et al, 1994). Despite this dramatic change, up until 1998, the government took the overwhelming responsibility for the investment in core infrastructures, the partial exceptions being the telecommunications and electricity sectors that were privatised towards the end of the 1980s (Moguillansky, 1999; Mideplan, 1999; Bitran and Saez, 1994). The sharp differentiation between these two periods can also be observed from relevant statistics.

GRAPH 1: CAPITAL FORMATION

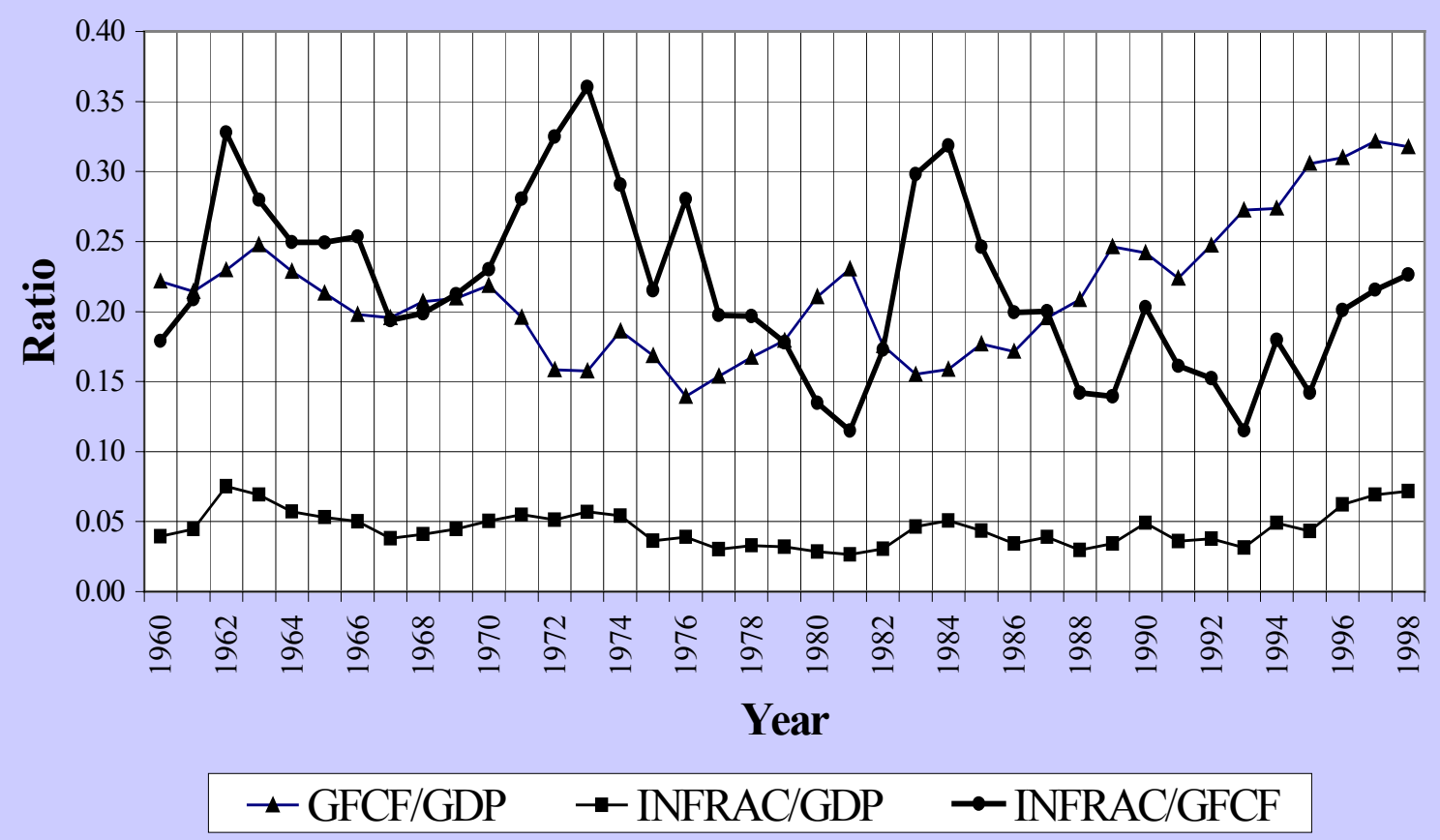


Graph 1 above shows a significant change in the share of the gross fixed capital formation (GFCF) in the gross domestic product (GDP). This share averaged 21 percent of GDP between 1960 and 72, falling to below 17 percent during the 1973-1990 period, and increasing to over 24 percent thereafter. The share of core infrastructure investment (INFRAC) in either GDP or GFCF, also shows a significant pattern change after 1973. In the former period, core infrastructure investment averaged 6 per cent of GDP and 29 percent of GFCF, while in the latter it only averaged 4 percent of GDP and 23 percent of GFCF, with a short jump between 1982 and 86, and another recovery after 1995. The annual average growth rate of infrastructure capital was much faster than that of GDP in the first period, i.e. 5.2 and 3.4 percent, respectively, while the converse is true in the second period, i.e. 3.4 and 4.7 percent, respectively. The latter hides the fact that the average annual growth rate of core infrastructure capital was only 2.3 percent between 1975 and 1993, significantly recovering thereafter. This shows that the effort in core infrastructure in relation to GDP over the second period was less important than that over the first one. But given that GDP grew at an average of around 7 percent since 1985, the core infrastructure investment recovered in absolute terms towards the end of the period, especially since 1995. However, if it is true that investment in core infrastructure is one of the main requirements for the unfolding of productive investment, then it is the relative, rather than the absolute, measurement that should matter.

Despite that the role of the state was significantly reduced in the second period, there still was some public involvement in the direction of the economy, especially since 1986 (Moguillansky 1999). The state was however the main if not the only investor in core infrastructure over the whole period. Its declining role may then be an indication of general infrastructure shortage. Can we establish whether that was the case? Can we 
discern infrastructure-induced productivity patterns for these two clearly differentiated institutional structures? Can we establish some patterns of investment complementarity/substitution over the period?

\section{Methodological Approach}

With the aim of assessing cost structures and thereby productivity, we attempt to estimate an empirical translog cost function, derived from the dual relationship between production and cost, as developed by Diewert (1971) and also proposed by Jorgenson and Lau (1974). This approach avoids the normal pitfalls of using production function, i.e. a mostly technical treatment, with an insufficient economic structure that prevents an explicit maximisation by firms. This normally leads to an excessively high elasticity and implied marginal productivity of infrastructures. Cost functions, in turn, make explicit consideration of factor input prices, resulting in measures for both the cost elasticity of output and the effect of infrastructure capital on the demand for other productive inputs. In addition the use of translog functions makes the exercise more flexible, for example avoiding the restrictive condition of imposing a unitary elasticity of substitution among inputs, as in the Cobb-Douglas specification (Nadiri \& Mamuneas, 1998).

\section{(i) Theoretical framework}

To assess the impact of infrastructure capital on the total production cost of the economy, and thereby on productivity, we use a cost function that depends on infrastructure, output, and the prices of capital and labour. Let us first set up an undefined production function, as follows: 
$Y_{t}=f\left(L_{t}, K_{t}, G_{t}\right)$

Where $Y_{t}$ is output, $L_{t}$ is labour, $K_{t}$ is non-infrastructure capital and $G$ is infrastructure capital. Equation (1) is a standard production function, augmented by infrastructure capital. Similar production functions have been widely used in the literature (see Gramlich 1994). However, as shown, the formulation of a production function has been also widely criticised as too restricted as they do not make explicit an underlying economic mechanism. Diewert (1971) introduced the duality concept between production and cost function, which can be used to formulate a more flexible functional form. Based on this, we can define a cost function as:

$\mathrm{C}=\mathrm{C}(\mathrm{W}, \mathrm{Y}, \mathrm{G})$

Where $\mathrm{W}$ is a vector of variable input prices. The main underlying assumptions of equation (2) are as follows. First, output, Y, is predetermined and thus is an exogenous variable, contrary to a production function. Second, the input price vector, W, is fixed and exogenous, implying that the economy chooses the combination of $\mathrm{K}$ and $\mathrm{L}$ that minimises its cost. From here, with two variable inputs of production, the total cost for the economy can be given by:

$\mathrm{C}=\mathrm{w}_{\mathrm{l}} \mathrm{L}+\mathrm{w}_{\mathrm{k}} \mathrm{K}$

Where $\mathrm{w}_{\mathrm{l}}$ is the price of labour and $\mathrm{w}_{\mathrm{k}}$ is the price of capital, while $\mathrm{L}$ and $\mathrm{K}$ are the costminimising quantities of these two variable inputs. Resorting to the envelope theorem we can then derive the economy's input demands: 


$$
L=\frac{d \ln C}{d \ln w l}, K=\frac{d \ln C}{d \ln w_{k}}, \lambda=\frac{d \ln C}{d \ln Y}, \text { and }-\lambda f_{g}=\frac{d \ln C}{d \ln G}
$$

Where $\lambda$ is the Langrange multiplier and $f_{g}$ is the partial derivative of equation (1) with respect to $G$, the latter representing the marginal product of infrastructure capital. Given output, a cost function should be homogenous of degree 1 in the prices of variable inputs to be well behaved:

$\mathrm{S}_{1}+\mathrm{S}_{\mathrm{k}}=1$

Where $S_{1}$ and $S_{k}$ are the shares of labour and capital in total cost, respectively. Under perfect competition, $\lambda=p$, where $p$ is the price of output. Therefore, the shares of production inputs and output in total costs can be written as:

$$
S_{l}=\frac{w L}{C}, S_{k}=\frac{w_{k} K}{C}, S_{y}=\frac{p y}{C} \text {, and } S_{g}=\frac{-p f_{g}}{C}
$$

The interpretation of the two production inputs and final output shares in total cost is straightforward. The latter share, $\mathrm{S}_{\mathrm{g}}$, however requires some clarification. This is a measure of the (negative) implicit value of the marginal product of infrastructure capital (see Lynd \& Rychmont, 1993). Notice that total cost is reduced when the marginal product of infrastructure capital is positive, and as a result the share of infrastructure capital in cost is negative. In this respect, $\mathrm{S}_{\mathrm{g}}$ can also represent the shadow price or willingness to pay for infrastructure capital. 
To capture empirically the effects of the infrastructure capital stock on the cost of the Chilean economy, we adopt the translog cost function of Jorgenson and Lau (1974). For our purpose, the specific translog function is a second order Taylor's approximation in logarithms to an arbitrary cost function, which is augmented with infrastructure capital. The latter is treated as a quasi-fixed input. The translog cost function therefore can take the form:

$$
\begin{aligned}
\ln C=\alpha_{0} & +\alpha_{i} \sum_{i=1}^{m} \ln w_{\mathrm{i}}+\alpha_{\mathrm{y}} \ln \mathrm{Y}+\alpha_{\mathrm{g}} \ln \mathrm{G}+\frac{1}{2} \sum_{i=1}^{m} \sum_{j=1}^{n} \beta_{i j} \ln w_{i} w_{j}+\frac{1}{2} \beta_{\mathrm{gg}} \ln ^{2} \mathrm{G} \\
& +\frac{1}{2} \beta_{\mathrm{yy}} \ln ^{2} \mathrm{Y}++\beta_{i y} \ln w i \ln Y+\beta_{i g} \ln w_{i} \ln G+\beta_{\mathrm{yg}} \ln \mathrm{Y} \ln \mathrm{G}
\end{aligned}
$$

Where i represents either capital k or labour 1. Applying Shephard's Lemma to equation (7), we obtain equations for the cost-shares of purchased inputs (or factor demands), infrastructure capital input (or shadow price) and final output. That is,

$\mathrm{S}_{\mathrm{i}}=\frac{d \ln C}{d \ln w_{i}}=\alpha_{\mathrm{i}}+\sum_{l=1}^{r} \alpha_{i l} \ln W_{i}+\beta_{\mathrm{iy}} \ln \mathrm{Y}+\beta_{\mathrm{ig}} \ln \mathrm{G}$

$\mathrm{S}_{\mathrm{y}}=\frac{d \ln C}{d \ln Y}=\alpha_{\mathrm{y}}+\beta_{\mathrm{iy}} \ln w_{\mathrm{i}}+\beta_{\mathrm{yy}} \ln \mathrm{Y}+\beta_{\mathrm{yg}} \ln \mathrm{G}$

$\mathrm{S}_{\mathrm{g}}=-\left(\frac{d \ln C}{d \ln G}\right)=-\left(\alpha_{\mathrm{g}}+\beta_{\mathrm{ig}} \ln \mathrm{W}_{\mathrm{i}}+\beta_{\mathrm{gg}} \ln \mathrm{G}+\beta_{\mathrm{yg}} \ln \mathrm{Y}\right)$

Where $S_{i}, S_{y}$ and $S_{g}$ are the cost-shares of the i-th input (or i-th factor demand), output and infrastructure capital (or shadow price of infrastructure), respectively. In turn, 
homogeneity of degree 1 in $w$ implies that $\sum_{i=1}^{m} S i=1$. The magnitudes and the signs of $\alpha_{\mathrm{g}}$, $\beta_{\text {ig }}$ in equation (8) capture the spill-over effect of infrastructure capital on both the total cost and the input shares of the economy.

Although the translog cost function can be estimated directly, it is customary to estimate equation (7) jointly with the factor demands from equation (8) in a common system. This simultaneous estimation is more efficient, as it incorporates more information (see Berndt 1992). Once we have estimated the parameters and the factor demands of equation (7), we can then proceed to estimate the cost elasticity of the infrastructure capital, which will allow us to determine whether its provision is cost saving. The cost elasticity of infrastructure capital is defined as:

$\eta_{\mathrm{g}}=\frac{d \ln C}{d \ln G}$

The elasticity estimate of $\eta_{\mathrm{g}}$ is supposed to reveal the productivity effect of infrastructure capital. In previous studies (e.g. Feltenstein and Ha, 1995), infrastructure capital is found to be cost saving, implying a negative sign for $\eta_{\mathrm{g}}$, which may also be an indication of infrastructure shortage. In addition, input demand adjustments and productivity effects can be measured by the elasticity of input shares with respect to infrastructure capital. That is,

$\eta_{\text {ig }}=\frac{d \ln S_{i}}{d \ln G}=\eta_{\mathrm{g}}+\frac{\beta_{\text {ig }}}{S_{i}}$

Where $\mathrm{i}=1, \mathrm{k}$. The estimation of (10) can reveal whether infrastructure capital induces the use of purchased inputs or not. Notice also that the sum of the productivity effect and 
input adjustment effect can offset each other. If $\eta_{\text {ig }}$ were greater, equal or less than zero, this would imply that the use of labour (capital) increased, remained unchanged or decreased, as infrastructure capital increases, respectively. This would also provide an indication about whether infrastructure capital complements/crowds-in or substitute/crowds-out non-infrastructure capital or labour.

\section{Data and Estimations}

All our data sources come directly from Chilean official institutions (e.g. Planning Ministry, Central Bank, Public Works Ministry and National Institute of Statistics) and compilations by other authors (especially, Moguillansky, 1999) from the same sources. As far as the infrastructure capital is concerned, we use a definition of infrastructure that is confined to transport, sewage and other utilities (e.g. water, electricity, and gas). That is, this is the so-called "core infrastructure" (see Diewert 1986). In turn, this is worked against total non-infrastructure capital $(\mathrm{K})$, rather than only private productive capital, and total labour in the economy (L). As indicated above, we now jointly estimate the equation system (7) and the input demands from (8) so as to secure a more efficient result than regressions applied separately to each equation, allowing estimations that adjust for contemporaneous correlation from crossed equations.

\section{(i) General Results Over the Period as a Whole}

Table 1 below presents the parameter estimates of the translog cost function (7). As expected, the parameters $\alpha_{1}$ and $\alpha_{k}$ are positive, which implies that the production costs increase as the value of inputs increase. In turn, the average impact of infrastructure 
capital on costs, $\alpha_{\mathrm{g}}$, has a negative sign, suggesting that an increase in infrastructure capital reduces the average cost of the economy. Therefore, core infrastructure capital can be treated as an input that increases the productivity of the economy. These results are in line with Feltenstein \& Ha (1995), Conrad \& Seitz (1993), Lynde \& Rychmond (1993), and Morrison \& Schwartz (1996).

Table 1: Translog Parameter Estimates

\begin{tabular}{|c|c|c|c|c|}
\hline & $\begin{array}{c}\text { Parameter } \\
\text { Estimate }\end{array}$ & Error & t-statistic & P-value \\
\hline$\beta_{\mathrm{kg}}$ & 0.1145 & 0.012 & 8.87 & {$[.000]$} \\
\hline$\beta_{\mathrm{ly}}$ & 0.0286 & 0.011 & 2.49 & $\begin{array}{l}\mathrm{L} .013] \\
{[.013]}\end{array}$ \\
\hline$\beta_{\text {II }}$ & 0.2052 & 0.008 & 22.9 & {$[.000]$} \\
\hline$\alpha_{1}$ & 0.5178 & 0.003 & 151.1 & {$[.000]$} \\
\hline$\alpha_{0}$ & 0.6135 & 0.009 & 66.35 & {$[.000]$} \\
\hline$\alpha_{g}$ & -0.3370 & 0.113 & -2.97 & {$[.003]$} \\
\hline$\beta_{g g}$ & 2.9440 & 0.567 & 5.18 & {$[.000]$} \\
\hline$\beta_{g y}$ & -2.0000 & 0.480 & -4.17 & {$[.000]$} \\
\hline$\alpha_{y}$ & 1.0830 & 0.130 & 8.29 & {$[.000]$} \\
\hline$\alpha_{\mathrm{yy}}$ & 1.2190 & 0.391 & 3.11 & {$[.002]$} \\
\hline$\alpha_{k}$ & 0.4820 & 0.003 & 140.7 & {$[.000]$} \\
\hline$\beta_{\mathrm{kl}}$ & -0.2050 & 0.008 & -22.9 & $\begin{array}{l}\mathrm{L} .000] \\
{[.000}\end{array}$ \\
\hline$\beta_{\mathrm{kk}}$ & 0.2050 & 0.008 & 22.9 & {$[.000]$} \\
\hline$\frac{\beta_{\mathrm{kK}}}{\beta_{\mathrm{ky}}}$ & -0.0280 & 0.011 & -2.49 & {$[.013]$} \\
\hline$\frac{\beta_{\mathrm{gh}}}{\beta_{\mathrm{lg}}}$ & -0.1140 & 0.012 & -8.87 & {$[.000]$} \\
\hline
\end{tabular}

Specification Tests:

Equation: Cost; Sum of squared residuals $=0.013$; R-squared $=0.997$; LM het. test $=0.0812$ [.776]; Durbin-Watson $=1.87$. Equation: Capital; Sum of squared residuals $=0.0038$; Rsquared $=0.948 ;$ LM het. test $=0.081$ [.776]; Durbin-Watson $=1.84$

Table 1 also shows that the parameter estimate of the average share of output in total cost, $\alpha_{y}$, is positive. This then confirms that the cost function is well behaved and specified. The parameter, $\beta_{\mathrm{ll}}, \beta_{\mathrm{kk}}$ and $\beta_{\mathrm{kl}}$ are the second order partial derivatives of the total cost function with respect to variable inputs. In the literature these parameters are referred to as 'constant share elasticities' and indicate the pattern of substitution of the variable input shares in total cost. Notice that in our theoretical specification only non- 
infrastructure capital stock and labour enter the total cost function, whereas infrastructure capital is taken as a quasi-fixed input of production. Therefore, we should not expect noninfrastructure capital and labour to be complements in the production process. As expected, our estimate of $\beta_{\mathrm{kl}}$ is negative and statistically significant.

The parameter estimates for $\beta_{\mathrm{lg}}$ and $\beta_{\mathrm{kg}}$ capture the spill-over effect of infrastructure capital on variable inputs. Moreover, they measure the 'factor bias effect' or 'input adjustment effect' of infrastructure capital on the cost-share of labour and noninfrastructure capital (Feltenstein \& Ha, 1995). Table 1 reports that the factor bias effect of infrastructure capital, $\beta_{\mathrm{kg}}$, on non-infrastructure capital is positive and statistically significant, indicating that the latter increases with a rise in the former. The opposite is true for the factor bias effect of infrastructure capital on labour, $\beta_{\mathrm{lg}}$. Notice, however, that the factor bias effect excludes the productivity impact of infrastructure capital and as a result the true nature of the relationship between infrastructure capital and either noninfrastructure capital or labour can be only clarified by estimating equation (10), as is shown in Table 3 below.

Within a non-homothetic translog cost function the "scale bias effect" is given by the parameter estimates of $\beta_{\mathrm{ky}}$ and $\beta_{\mathrm{ly}}$. These estimates show the change of non-infrastructure and labour shares in total cost caused by a change in the level of output. Table 1 reports a negative (positive) value for $\beta_{\mathrm{ky}}\left(\beta_{\mathrm{ly}}\right)$, implying that non-infrastructure capital decreases with an increase in output, while the opposite is true for the impact of the latter on labour share. 
The coefficient $\beta_{\mathrm{yy}}$ represents cost flexibility and shows that the marginal cost decreases as output expands. In turn, the parameter $\beta_{\mathrm{yg}}$ represents the marginal cost response to changes in infrastructure capital, indicating whether infrastructure capital is (marginally) cost reducing or cost increasing. The data suggests that public infrastructure reduces marginal cost significantly.

\section{(ii) Evolution of Results over the Period}

Table 2 below shows the total cost elasticity with respect to infrastructure capital for the period 1960-1998. Infrastructure capital growth appears to increase slightly the production costs up to 1971 , therefore reducing slightly the productivity of the economy. From 1972 on, the reverse seems true, especially after 1973.

This would appear to be at odds with the higher co-ordinating mechanism that was apparent in the former period. Before 1973, the Chilean state had strong developmentalist leanings, which acted in a semi-corporativist fashion, via a network of official and informal channels that secured some stable forms of protected partnership between the public and the industrialising sections of the private sector, some times termed a "clientelistic" democracy. These took the form of a system of official committees, in which the private sector actively participated, and a network of direct and indirect lobbies that operated via political parties and also labour and bosses unions. These translated into a system of regulations, restrictions, and selective advantage, which both generated the standard economic inefficiencies associated with rent-seeking activities and also the wellobserved social and economic stability associated with it, especially in what was a fast 
socially developing democracy. This involved land reform, union rights, social security systems, universal education and health, vocational training, and the like.

Table 2: Elasticity of Cost with Respect to Public Infrastructure

\begin{tabular}{|lc|cc|}
\hline Date & $\boldsymbol{\eta}_{\mathbf{g}}$ & Date & $\boldsymbol{\eta}_{\mathbf{g}}$ \\
\hline Dec-60 & -0.638 & Dec-80 & 0.4177 \\
Dec-61 & -0.605 & Dec-81 & 0.3186 \\
Dec-62 & -0.438 & Dec-82 & 0.6216 \\
Dec-63 & -0.323 & Dec-83 & 0.7957 \\
Dec-64 & -0.200 & Dec-84 & 0.7915 \\
Dec-65 & -0.086 & Dec-85 & 0.8092 \\
Dec-66 & -0.160 & Dec-86 & 0.7640 \\
Dec-67 & -0.130 & Dec-87 & 0.7221 \\
Dec-68 & -0.106 & Dec-88 & 0.6377 \\
Dec-69 & -0.062 & Dec-89 & 0.5114 \\
Dec-70 & 0.0179 & Dec-90 & 0.5479 \\
Dec-71 & -0.028 & Dec-91 & 0.4741 \\
Dec-72 & 0.1237 & Dec-92 & 0.3416 \\
Dec-73 & 0.4400 & Dec-93 & 0.2814 \\
Dec-74 & 0.5329 & Dec-94 & 0.3326 \\
Dec-75 & 0.8439 & Dec-95 & 0.2776 \\
Dec-76 & 0.8363 & Dec-96 & 0.3708 \\
Dec-77 & 0.707 & Dec-97 & 0.4952 \\
Dec-78 & 0.6101 & Dec-98 & 0.6850 \\
Dec-79 & 0.5328 & & \\
& & & \\
\hline
\end{tabular}

This system became more cumbersome and in-efficacious over time, until its collapse in early 1970s, and particularly after 1973. In the latter date, which also coincided with the first oil shock, the mentioned social contract, which had operated since the 1930s, was unceremoniously and violently abolished by a military take-over that lasted 17 years (Velazco, 1994).

This system of interrelations between public and private decisions and between public infrastructure and other public productive capital, which is typically associated with an import-substitution strategy, does not appear to have translated into improved productive co-ordination, and therefore improved use of resources, at least over the 1960-1972 
period. While for the 1973-98 period the opposite appears to have occurred. However, the issue of co-ordination is normally associated more with static economic growth than with dynamic institutional development, like that of Chile over the former period. Therefore, a good deal of public expenditure was motivated by the societal rationale of developing infrastructures to secure social cohesion and coverage for a socially integrated development, and not just for the more narrow economic rationale of accommodating productive pressures or inducing higher production and productivity. The result is that the former period may be characterised as one of chronic surplus of core infrastructure. As indicated above (see Introduction), there was a significant growth in infrastructure capital over this period, which was much faster than GDP growth. This simply implies that the economy seemed to run with high levels of idle infrastructure capacity; therefore, additions to it where not transformed into higher output, but only into higher production costs, but not necessarily higher social costs. Contrariwise, for the 1973-1990 period, there appears to be a chronic infrastructure shortage. This may be the consequence of the smaller effort in infrastructure formation over the period (see Introduction).

Table 3 below, in turn, reports the elasticity of substitution between infrastructure capital and either non-infrastructure capital or labour. We can observe that infrastructure capital is a complement to non-infrastructure capital since 1964, as implied by the positive sign of $\eta_{\mathrm{kg}}$. But actually between 1960 and 1973 there appears to be some weak, probably neutral effect between the two. It is only after 1973 that infrastructure appears as a significant complement to non-infrastructure capital. This suggests that infrastructure capital enhanced the use of non-infrastructure capital especially in the 1973-1990 period, implying a crowding-in effect from infrastructure to non-infrastructure capital. This is an 
interesting result, as it suggests that the change in economic structure and dynamics also consolidated a change in the nature of the relationship between these two types of capital.

Table 3: The Effect of Public Infrastructure of Private Inputs of Production

\begin{tabular}{|ccc|ccc|}
\hline Date & $\boldsymbol{\eta}_{\mathbf{k g}}$ & $\boldsymbol{\eta}_{\mathbf{l g}}$ & Date & $\boldsymbol{\eta}_{\mathbf{k g}}$ & $\boldsymbol{\eta}_{\mathbf{l g}}$ \\
\hline Dec-60 & -0.391 & -0.852 & Dec-80 & 0.648 & 0.190 \\
Dec-61 & -0.354 & -0.816 & Dec-81 & 0.558 & 0.099 \\
Dec-62 & -0.190 & -0.653 & Dec-82 & 0.882 & 0.417 \\
Dec-63 & -0.090 & -0.548 & Dec-83 & 1.033 & 0.574 \\
Dec-64 & 0.029 & -0.428 & Dec-84 & 1.015 & 0.557 \\
Dec-65 & 0.150 & -0.308 & Dec-85 & 1.026 & 0.566 \\
Dec-66 & 0.080 & -0.379 & Dec-86 & 0.972 & 0.509 \\
Dec-67 & 0.105 & -0.352 & Dec-87 & 0.922 & 0.454 \\
Dec-68 & 0.137 & -0.322 & Dec-88 & 0.833 & 0.361 \\
Dec-69 & 0.180 & -0.279 & Dec-89 & 0.711 & 0.243 \\
Dec-70 & 0.272 & -0.190 & Dec-90 & 0.753 & 0.288 \\
Dec-71 & 0.266 & -0.215 & Dec-91 & 0.683 & 0.220 \\
Dec-72 & 0.425 & -0.060 & Dec-92 & 0.555 & 0.094 \\
Dec-73 & 0.666 & 0.207 & Dec-93 & 0.500 & 0.040 \\
Dec-74 & 0.762 & 0.304 & Dec-94 & 0.553 & 0.093 \\
Dec-75 & 1.084 & 0.625 & Dec-95 & 0.498 & 0.039 \\
Dec-76 & 1.072 & 0.613 & Dec-96 & 0.593 & 0.135 \\
Dec-77 & 0.945 & 0.486 & Dec-97 & 0.715 & 0.256 \\
Dec-78 & 0.843 & 0.385 & Dec-98 & 0.907 & 0.448 \\
Dec-79 & 0.756 & 0.297 & & & \\
\hline
\end{tabular}

As before, the weak and erratic relationship between these two types of capital in the 1960-1973 period can be explained in similar terms to the issue of cost/productivity above. It is well known that in Chile the import-substitutive strategy, with their focus on industrialisation, via especial facilities to import capital goods, brought in significant levels of "inappropriate technology". This translated in capital intensive techniques that both absorbed relatively low levels of industrial employment and were too productive for the narrow level of the domestic market, at a time when there was a policy bias against exports. This resulted in an economy that operated with chronic levels of industrial idle capacity and scale-economy dis-advantage (Bothworth \& Dornbusch, 1994; FrenchDavis, 1973). Therefore, higher infrastructure availability did not appear to have stimulated additional non-infrastructure capital formation, because of a mix of societal 
and developmental rationales and their incentive consequences. In dramatic turn of circumstances, after 1973, with the institutional dismantling of the import substitution regime and the drastic abandonment of social policy, private capital became strongly correlated with infrastructure availability, the more so as core infrastructure investment was significantly reduced, apparently generating chronic shortages of the latter.

Finally, the elasticity of labour demand with respect to infrastructure capital is negative until 1972, and positive but mostly weak thereafter, suggesting that these two inputs were substitutes or little related. For the 1960-1973 period, these results agree with those of Feltenstein and Ha (1995) and Mamatzakis (1999). However, since then, these two inputs appear to be highly independent. The explanation for the former may be found in the prevailing full-employment policies that prevented the firing of organised workers, even in recessions, and as indicated the prevailing existence of rather high manufacturing idle capacity, even in normal times (Ffrench-Davis, 1973). This implies that the stimulus of infrastructure formation on non-infrastructure sectors did not translate into more employment, but into more output with similar or slightly lower labour employment. This, plus the normal expected substitutive effect of infrastructure on labour, may account for the negative infrastructure elasticity of labour to infrastructure formation.

Contrariwise, in the neoliberal 1973-95 period, a number of traits like the full deregulation of the labour market, the lifting of manufacturing protections and the liberalisation of external trade and capital flows appear to generate a positive but overall weak complementary effect between labour and infrastructure formation. The key for this positive relationship may be in the massive unemployment that the above policies generated. It is to be noticed that between 1974 and 1988, the rate of unemployment 
averaged nearly 15 percent, almost trebling as compared to the $1960-73$ period. It is only from 1989 that this rate does go down to around 6 percent. The meaning of this is simply that any infrastructure capital formation, impinging on the recoveries of noninfrastructure capital and output, may have had some marginally beneficial effects on employment.

\section{Conclusions}

An attempt has been made in this study to examine the impact of infrastructure capital on the production structure of the Chilean economy. To this purpose we opt for a flexible methodological framework in terms of the dual cost function. Thus, we take into the account the criticism in the literature about the use of rigid production functions, which lack an underlying economic mechanism (Feltenstein \& Ha, 1995; Lynde \& Rychmond, 1993). The results reveal that our translog cost function is well behaved, i.e. concave in the prices of non-infrastructure capital and labour, and non-decreasing in output, and that the infrastructure capital exhibits a significant productive impact on the Chilean economy.

Our main conclusion is that there is a clear differentiation in terms of costs, productivity and complementarity between our two sub-periods, i.e. between the 1960-1972 developmentalist period and the 1973-98 neoliberal period. First, infrastructure formation appears to be cost reducing for the economy only in the latter period, which would imply that infrastructure-induced productivity increases for the same period. Second, infrastructure capital formation appears to be weakly related to non-infrastructure capital formation in the first period, while it appears to crowd-in non-infrastructure investment 
significantly in the second period. This result may be associated with both the political economy of the period and the existence of a surplus and a shortage of infrastructure capital in the former and latter periods, respectively. Finally, labour input and infrastructure formation appear to be either substitutive in the first period or weakly complementary in the second period. These differences in strength may be accounted by the dramatic differences in unemployment on account of the very different policy packages and institutional structures between these two periods. 


\section{References}

Albala-Bertrand, J.M. (1999) Industrial Interdepence Change in Chile: 1960-90 a comparison with Taiwan and South Korea in International Review of Applied Economics, Vol. 13, No.2, 1999.

Banco Central de Chile Boletin Mensual (Santiago, Banco Central, Monthly).

Bitran, E. and Saez, R. "Privatization and Regulation in Chile" in B.Bosworth, R. Dornbusch, and R. Laban (Eds.) (1994) The Chilean Economy (Washington D.C.,The Brookings Institution), pp.329-378.

Bosworth, B., Dornbusch, R. and Laban, R. (Eds.) (1994) The Chilean Economy (Washington D.C., The Brookings Institution).

Conrad, K. and H. Seitz (1994), "The Economic Benefits of Public Infrastructure", Applied Economics, 26, pp 303-11.

Diewert, W. (1971) "An Application of the Shephard Duality Theorem: a Generalised Leontief Production Function,”, 79, 461-507, Journal of Political Economy.

Diewert, W. E. (1986), "The Measurement of the Economic Benefits of Infrastructure Services", in: Lecture Notes in Economics, vol. 278, Springer, Berlin.

Feltenstein, A. and J. Ha (1995) "The Role of Infrastructure in Mexican Economic Reform", The World Bank Economic Review, vol. 9, pp. 287-304.

French-Davis, R. (1973) Politicas Economicas en Chile: 1952-1970 (Santiago, Ediciones Nueva Universidad).

Gramlich E. M (1994), "Infrastructure Investment: a Review Essay", vol. XXXII, Journal of Economic Literature, Sept., 1176-96.

Jorgenson, D. W., and L. J. Lau, (1974) "Duality and Differentiability in Production," 9, 23-42, Journal of Economic Theory.

Lynde, C. and J. Richmond (1993), "Public Capital and Long-Run Costs in UK Manufacturing", The Economic Journal, Vol.103, No.419, p.880.

Mamatzakis, E.C. (1999) 'Testing for Long Run Relationship Between Infrastructure and Private Capital Productivity: a Time Series Analysis for the Greek industry,' Applied Economics Letters, April, pp. 243-246.

Meller, P. (1990) Three policy Experiments: The Case of Chile, in: J. Williamson (Ed.) Latin American Adjustment. How Much Has Happened? (Washington D.C., Institute for International Economics), pp.54-85. 
Mideplan (1999) Evolucion y Estructura de la Inversion Publica en Chile (Santiago, Mideplan).

Moguillansky, G. (1999) La Inversion en Chile. El Fin de Un Ciclo de Expansion? (Santiago, CEPAL, Fondo de Cultura Economica).

Morrison, C. J. and A. Schwartz (1996), "State Infrastructure and Productive Performance," The American Economic Review, pp 1094-1111.

Nadiri, M.I. and Mamuneas, T.P. (1998) Contribution of Highway Capital to Output and Productivity Growth in the US Economy and Industries (USA, Office of Transportation Policy Studies, http://www.fhwa.dot.gov////////policy/referenc.htm).

Odeplan (1971) Inversion Publica en el Periodo 1961-70 (Santiago, Odeplan)

Parkin, V. (1983) Economic Liberalism in Chile 1973-82, Cambridge Journal of Economics, Vol. 7, pp.101-124.

Taylor, L. (Ed.) (1993) The Rocky Road to Reform, Adjustment, Income and Growth in Developing Countries (Cambridge Mass., MIT Press).

Velazco, A. "The State and Economic Policy: Chile 1952-92" in B.Bosworth, R. Dornbusch, and R. Laban (Eds.) (1994) The Chilean Economy (Washington D.C.,The Brookings Institution), pp.379-430.

Wisecarver, D. (Ed.) (1992) El Modelo Economico Chileno (Santiago, Universidad Catolica). 


\section{Q Queen Mary \\ University of London}

This working paper has been produced by the Department of Economics at Queen Mary, University of London

Copyright $\odot 2001$ Jose Miguel Albala-Bertrand and Emmanouel C. Mamatzakis. All rights reserved.

Department of Economics

Queen Mary, University of London

Mile End Road

London E1 4NS

Tel: +44 (0)20 78825096 or Fax: +44 (0)20 89833580

Email: j.conner@qmw.ac.uk

Website: www.econ.qmw.ac.uk/papers/wp.htm 